\title{
SYSTEMATIC REVIEW
}

\section{Conventional radiography and cross-sectional imaging when planning dental implants in the anterior edentulous mandible to support an overdenture: a systematic review}

\author{
${ }^{1,2} \mathrm{~A}$ M Shelley, ${ }^{3} \mathrm{~A}-\mathrm{M}$ Glenny, ${ }^{3} \mathrm{M}$ Goodwin, ${ }^{2} \mathrm{P}$ Brunton and ${ }^{3} \mathrm{~K}$ Horner \\ ${ }^{1}$ Dental Practice, Denton, UK; ${ }^{2}$ The Leeds Dental Institute, University of Leeds, Leeds, UK; ${ }^{3}$ School of Dentistry, University of \\ Manchester, Manchester, UK
}

\begin{abstract}
The objectives for this systematic review were to determine if the pre-operative availability of cross-sectional imaging, such as cone beam CT, has a diagnostic impact, therapeutic impact or impact on patients' outcome when placing two dental implants in the anterior mandible to support an overdenture. The Cochrane Oral Health Group's Trials Register (CENTRAL), MEDLINE® and Embase were searched up to, and including, February 2013. Studies were considered eligible for inclusion if they compared the impact of conventional and crosssectional imaging when placing dental implants in sites including the anterior mandible. An adapted quality assessment tool was used for the assessment of the risk of bias in included studies. Pooled quantitative analysis was not possible and, therefore, synthesis was qualitative. Of 2374 potentially eligible papers, 5 studies were included. Little can be determined from a synthesis of these studies because of their small number, clinical diversity and high risks of bias. Notwithstanding, it may be tentatively inferred that cross-sectional imaging has a therapeutic impact in the more challenging cases. In terms of impact, this review has found no evidence to support any specific imaging modality when planning dental implant placement in any region of the mouth. Therefore, those who argue that cross-sectional imaging should be used for the assessment of all dental implant sites are unsupported by evidence.
\end{abstract}

Dentomaxillofacial Radiology (2014) 43, 20130321. doi: 10.1259/dmfr.20130321

Cite this article as: Shelley AM, Glenny A-M, Goodwin M, Brunton P, Horner K. Conventional radiography and cross-sectional imaging when planning dental implants in the anterior edentulous mandible to support an overdenture: a systematic review. Dentomaxillofac Radiol 2014; 43: 20130321.

Keywords: dental implant; radiography; comparison systematic review

\section{Introduction}

Many edentulous patients struggle to function, leading to a decline in their quality of life. ${ }^{1}$ This is particularly true of lower dentures where looseness and discomfort are common. ${ }^{2}$ The placement of two dental implants in the anterior mandible allows methods of additional retention to be used to support complete lower dentures and is regarded by some authorities as the first choice of treatment for the edentulous mandible. ${ }^{1,3}$

Correspondence to: Mr Andrew M Shelley. Email: andrew@andrewshelley.com Received 28 August 2013; revised 16 November 2013; accepted 20 November 2013
Alveolar resorption following tooth extraction can leave the anterior mandible very shallow, narrow or knife-edged. ${ }^{4}$ This increases the risks of perforation of the lingual cortical plate during the preparation for the placement of dental implants. Perforation has the potential to traumatize lingual vessels causing severe bleeding and a life-threatening upper airway obstruction. ${ }^{5}$ A search of literature reveals that at least 20 cases have been reported. ${ }^{6-23}$ Some of these cases are reported as "potentially fatal" fatal". ${ }^{17}$ Many of the patients in these reports were fortunate enough to be in a situation where an 
emergency tracheotomy could be performed to save their lives. $6,10,11$

It has been suggested that pre-operative crosssectional imaging is advisable, or should be routine, to reduce the likelihood of such an event. ${ }^{5,24-26}$ Nonetheless, a pre-operative appreciation of the form of the anterior mandible may also be gained through clinical examination and conventional radiography. ${ }^{27}$ It is, therefore, unclear whether the pre-operative availability of cross-sectional imaging, such as cone beam CT, has an impact on pre-operative assessment, treatment or outcome in such cases.

A number of authors have proposed a hierarchy on levels of efficacy for the evaluation of diagnostic imaging. ${ }^{28-30}$ Fryback and Thornbury ${ }^{31}$ proposed six levels: technical efficacy, diagnostic accuracy efficacy, diagnostic thinking efficacy, therapeutic efficacy, patient outcome efficacy and societal efficacy. These authors further stated "A key feature of this model is an understanding that for an imaging procedure to be efficacious at a higher level in this hierarchy it must be efficacious at lower levels". Many studies have been conducted to investigate technical efficacy and diagnostic accuracy efficacy of cross-sectional imaging methods, and these have been the subject of systematic review. ${ }^{32-35}$ With respect to dental implant planning, a systematic review by Ribeiro-Rotta et $\mathrm{al}^{36}$ posed the question "What is the diagnostic accuracy of the clinical methods used to assess bone density, bone quantity and bone quality prior to and during dental implant placement?". More recently, a study by Al-Ekrish and Ekram $^{37}$ specifically considered the accuracy and reliability of multidetector CT and cone beam CT in the assessment of dental implant site dimensions. These authors found that the mean error was $0.75 \mathrm{~mm}$ for multidetector CT images and $0.49 \mathrm{~mm}$ for cone beam CT images.

Nevertheless, to understand the impact of crosssectional imaging, investigation is necessary at the other higher levels of efficacy.

The research question for this review was "Does the use of cross-sectional imaging prior to dental implant placement in the anterior edentulous mandible have diagnostic thinking efficacy, therapeutic efficacy or patient outcome efficacy compared with conventional imaging alone, when placing two dental implants in the anterior mandible to support an overdenture?". The definitions of diagnostic thinking efficacy, therapeutic efficacy and patient outcome efficacy were those used by Fryback and Thornbury. ${ }^{31}$ In the context of this review, diagnostic thinking efficacy included, for example, studies where an assessment of image helpfulness was made in assessing potential implant sites. An example of therapeutic efficacy is an investigation into the change in an operator's treatment plan according to the availability of different image types. Research into patient outcome efficacy might, for example, include assessment of post-operative morbidity or longevity of implants placed with the guidance of different image types.

\section{Methods and materials}

\section{Inclusion criteria}

Inclusion criteria were set in advance of a literature search. Studies were included where the subjects were human, or human simulations, with complete mandibular edentulism and where implants were planned for the interforaminal region to support a complete lower overdenture. In vivo or in vitro studies were acceptable. Nevertheless, the possibility was recognized that insufficient studies might be found, which investigated dental implant placement in the anterior mandible prior to provision of an overdenture. It was therefore agreed that, if insufficient studies were identified, those that investigated dental implant placement anywhere in the mouth, for any purpose, but including the anterior mandible, would be acceptable. Studies were included where the intervention was cross-sectional imaging, of all types, prior to dental implant placement. This included, for example, conventional tomography, medical (multislice) CT and cone beam CT. Studies were sought where the comparator was conventional two-dimensional radiography prior to dental implant placement. The outcome had to be diagnostic thinking, therapeutic efficacy or patient outcome as defined by Fryback and Thornbury. ${ }^{31}$ The following study designs were considered: before-after studies, randomized controlled studies or other observational study designs. Studies were included where the primary purpose was cross-sectional imaging for assessment prior to dental implant placement rather than being primarily for the construction of a computer generated surgical guide. Only those studies in the English language or with an English language abstract were acceptable. The following publication types were considered: peer-reviewed journals, non-peer-reviewed journals, reports, book chapters, conference abstracts, theses, informal reports and on-going studies where complete data were available.

\section{Search strategy}

A rapid scoping exercise of bibliographic databases was carried out, which identified 13 studies. On the basis of titles and abstracts, six appeared to meet the inclusion criteria $^{38-43}$ and seven were "near misses". 44-50 These studies were used to pilot and refine the search strategy of bibliographic databases by conducting trial searches. The aim was to return all of those studies that met the inclusion criteria and to exclude, at least, some of those that did not. Sensitivity in the search was favoured over specificity to avoid missing studies that might be included in the review. Three bibliographic databases, PubMed/MEDLINE®, OVID/Embase and the Cochrane CENTRAL database were searched up to and including February 2013. Each allowed different search terms. The final OVID/Embase search is presented in Figure 1.

Additional searches were carried out. The reference sections of relevant studies identified in the search of bibliographic databases were hand searched, and the 
reference sections of relevant published guideline documents were similarly searched. ${ }^{51-61}$ The web of Knowledge Science Citation Index was used to identify studies that had cited the rapid scope studies. Of these six studies identified by rapid scoping, four were from the journal "Clinical Oral Implants Research". The content pages of this journal were searched to identify further studies. The International Association of Dental Research website publishes an online archive of its conference proceedings. This database was searched for relevant research. Two online resources were used to search for relevant studies. These were CinicalTrials.gov (www.clinicaltrials.gov) and the World Health Organization's International Clinical Trials Registry (www.who.int/trialsearch). Two online resources were used to search for relevant theses. These were "Proquest Dissertations and Theses" (www. proquest.co.uk) and "EthOS ElectronicTheses" (www. ethos.bl.uk). The OpenGrey website was also searched for relevant research (www.opengrey.eu). Finally, the review was registered with PROSPERO, the International Prospective Register of Systematic Reviews. This enabled other workers to contact the review team with further information on any relevant studies.

\section{Study selection}

After removal of duplicates, the lead author reviewed titles to exclude studies that were clearly irrelevant. Abstracts were then reviewed to identify relevant articles that would be retrieved for full text review. Where a study narrowly failed to meet the inclusion criteria, the reason was recorded and decisions were re-examined by a second reviewer. Detailed assessment of full papers was carried out independently by two reviewers. Disagreements were resolved by consensus. Reviewers were not blinded to authors, institution or study results during the study selection process. This has been demonstrated to be of limited value whilst considerably increasing the difficulty of the process of study selection. ${ }^{62,63}$

\section{Data extraction}

A pilot study was carried out to develop a data extraction form. At this stage, it had become clear that one of the six original rapid scope studies, that were thought to meet the selection criteria, did not include implants placed in the anterior mandible. ${ }^{39}$ This study included only implants placed in the posterior maxilla. Therefore, five remaining rapid scope studies were used to pilot the data extraction form. ${ }^{38,40-43}$ The starting point was the data extraction form used by Albon et $\mathrm{al}^{64}$ in their neuroimaging review. The final data extraction form was in Microsoft $\AA$ Excel ${ }^{\mathrm{TM}}$ format. Data extraction was first carried out independently by two reviewers. All discrepancies were resolved by discussion.

\section{Quality assessment}

All studies identified in the rapid scoping exercise were of the before-after design. A quality assessment tool for before-after studies has been developed by Meads and Davenport ${ }^{65}$ and was adapted for use in this review. The quality assessment form was used as shown in Figure 2. Quality assessment was first carried out independently by two reviewers. All discrepancies were resolved by discussion.

\section{Synthesis}

A table was made of study characteristics, outcomes and quality assessment (Table 1). Following discussion with a second reviewer, a subjective judgment was made as to whether each study suggested change in the treatment plans following the availability of cross-sectional imaging. From this, two graphical representations were made. Each study was placed in a column according to whether it suggested change after cross-sectional imaging, no change after cross-sectional imaging or if there was no strong suggestion. Some studies had bigger sample sizes of implants than others. Therefore, in the first graphical representation, each column height is proportional to the number of implants placed (Figure 3). Some studies also had a larger number of evaluators than others. Therefore, a second graphical representation was made with each column height proportional to the number of evaluators (Figure 4).

Pooled quantitative analysis was not possible because of the small number of studies identified, their low quality and their heterogeneity. Analysis, therefore, remained qualitative, and conclusions were based on trends suggested in Table 1 and the graphical representations in Figures 3 and 4.

\section{Results}

A Preferred Reporting Items for Systematic Reviews and Meta-Analyses diagram of the search process, with results and reasons for exclusion, is presented in Figure 5. No studies were identified that related solely to placement of implants in the anterior mandible. No relevant systematic reviews were identified during the search process. No randomized controlled trials were returned, and there were no cohort or case-control studies. All five studies, which were identified in the search, were of the before-after design. All investigated change in treatment plan following the availability of cross-sectional imaging. Therefore, these studies were relevant only to therapeutic efficacy.

\section{Quality assessment}

The included studies were generally assessed being of low methodological quality. All discrepancies were resolved by discussion. A summary of this subjective quality assessment is presented in the final column of Table 1 .

\section{Synthesis}

Study characteristics are presented in Table 1.

It was possible to separate the data for implants placed in the anterior mandible only in the 2011 study by Schropp et al. ${ }^{42}$ In this study, only three implants 


\begin{tabular}{|c|c|c|}
\hline Emtree terms & & exp tooth prosthesis/ \\
\hline
\end{tabular}

Terms to find

dental

implant

studies

Free text terms

4. (Dental adj5 implant*).ti,ab.

5. (Implant adj5 dentistry).ti,ab.

6. (Oral adj5 implant $\left.{ }^{\star}\right)$.ti,ab.

7. (endosseous adj5 implant ${ }^{\star}$ ).ti,ab.

Combined with OR

Emtree terms

Terms to find radiology studies

Free text terms

Combined with OR
9. $\quad$ exp tomography/

10. exp three dimensional imaging/

11. exp dental radiology/

12. exp tooth radiography/

13. Imag*.ti,ab.

14. Tomograph*.ti,ab.

15. Radiolog*.ti,ab.

16. Radiograph*.ti,ab.

17. 9 or 10 or 11 or 12 or 13 or 14 or 15

or 16
Terms to find studies that investigate planning or assessment of cases

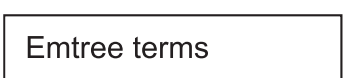

18.

19.

20.

Combined with OR

21.

exp outcome assessment/

exp clinical practice/

exp dental procedure/

18 or 19 or 20

\section{Terms to find comparative studies}

Emtree terms

Free text terms

Combined with OR
22. exp comparative study/

23. exp comparative effectiveness/

24. ((compar* or chang $\left.{ }^{*}\right)$ and (outcome* or plan*)).ti,ab

25 or 23 or 24
Figure 1 OVID/Embase search.

were placed in the anterior mandible. In all other studies, the number of implants placed in the anterior mandible was unclear. Therefore, further analysis of implants
Overall combination of each section with AND, 8 and 17 and 21 and 25 placed in the anterior mandible only was not performed. Unfortunately, in the 1994 study by Reddy et al, ${ }^{41}$ the number of implants placed was not recorded. 


\begin{tabular}{|c|c|c|c|c|c|c|c|}
\hline \multicolumn{2}{|c|}{ Author } & & \multicolumn{2}{|l|}{ Year } & & & \\
\hline \multicolumn{8}{|c|}{ Study title } \\
\hline No. & & Item & & $\mathrm{N} / \mathrm{A}$ & Yes & Unclear & No \\
\hline 1 & \multicolumn{3}{|c|}{$\begin{array}{l}\text { Was the spectrum of patients representative of patients who will } \\
\text { receive imaging in practice? }\end{array}$} & & & & \\
\hline 2 & \multicolumn{3}{|c|}{ Were the selection criteria clearly described? } & & & & \\
\hline 4 & \multicolumn{3}{|c|}{$\begin{array}{l}\text { Is the period between conventional imaging and } 3 \mathrm{D} \text { imaging short } \\
\text { enough to be reasonably sure that the target condition did not } \\
\text { change between the two tests? }\end{array}$} & & & & \\
\hline 5 & \multicolumn{3}{|c|}{$\begin{array}{l}\text { Did the whole sample or a random selection of the sample receive } \\
\text { verification using a reference standard of diagnosis? } \\
\text { (Yes for whole sample or random selection. No if neither.) }\end{array}$} & & & & \\
\hline 6 & \multicolumn{3}{|c|}{$\begin{array}{l}\text { Did the patients receive the same } 3 \mathrm{D} \text { imaging regardless of } \\
\text { conventional imaging? }\end{array}$} & & & & \\
\hline 8 & \multicolumn{3}{|c|}{$\begin{array}{l}\text { Was the execution of the conventional imaging described in } \\
\text { sufficient detail to permit replication of the test? }\end{array}$} & & & & \\
\hline 9 & \multicolumn{3}{|c|}{$\begin{array}{l}\text { Was the execution of the 3D imaging described in sufficient detail to } \\
\text { permit its replication? }\end{array}$} & & & & \\
\hline 10 & \multicolumn{3}{|c|}{$\begin{array}{l}\text { Were the conventional imaging results interpreted without } \\
\text { knowledge of the results of the } 3 D \text { imaging? }\end{array}$} & & & & \\
\hline 11 & \multicolumn{3}{|c|}{$\begin{array}{l}\text { Were the 3D imaging results interpreted without knowledge of the } \\
\text { conventional imaging? }\end{array}$} & & & & \\
\hline 12 & \multicolumn{3}{|c|}{$\begin{array}{l}\text { Were the same clinical results available when imaging results were } \\
\text { interpreted as would be available when the imaging is used in } \\
\text { practice? }\end{array}$} & & & & \\
\hline 13 & \multicolumn{3}{|c|}{ Were uninterpretable/intermediate imaging results reported? } & & & & \\
\hline 14 & \multicolumn{3}{|c|}{ Were withdrawals from the study explained? } & & & & \\
\hline A & \multicolumn{3}{|c|}{ Were patients recruited consecutively? } & & & & \\
\hline $\mathrm{C}$ & \multicolumn{3}{|c|}{$\begin{array}{l}\text { Was the study and/or collection of clinical variables conducted } \\
\text { prospectively? }\end{array}$} & & & & \\
\hline B & \multicolumn{3}{|c|}{$\begin{array}{l}\text { What was the explanation for patients } \\
\text { who did not receive 3D imaging? } \\
\text { (Dark grey for good quality, light grey for poor quality.) }\end{array}$} & & & & \\
\hline D & \multicolumn{3}{|c|}{$\begin{array}{l}\text { Who performed the clinical evaluation } \\
\text { and image analysis? } \\
\text { (Dark grey for good quality, light grey for poor quality.) }\end{array}$} & & & & \\
\hline
\end{tabular}

Numbering is unchanged from original sources. Numbered items are from Quadas 1.

Questions 3 \& 7 were removed by Meads and Davenport

Letters are additional questions from Meads and Davenport

Overall subjective quality assessment (Dark grey for good quality, light grey for poor quality.)

Figure 2 Quality assessment form modified from the originally published works of Meads and Davenport. ${ }^{65} 3 \mathrm{D}$, three dimensional. 

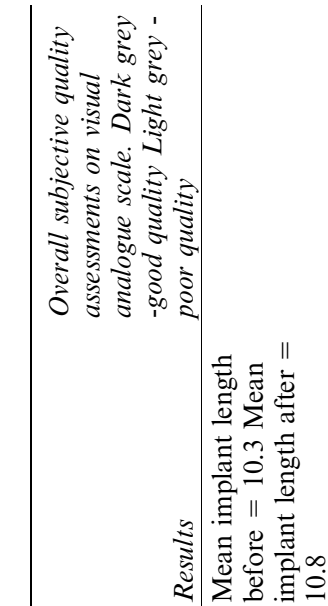
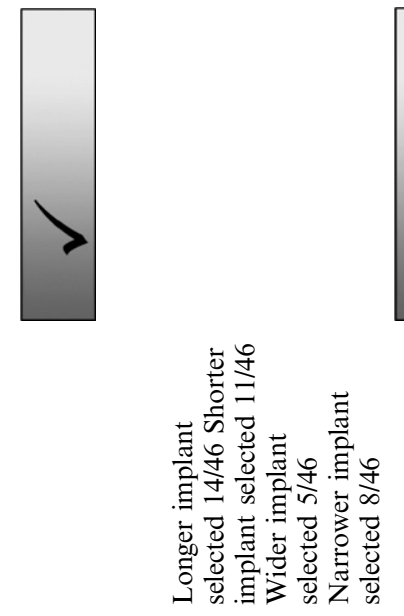
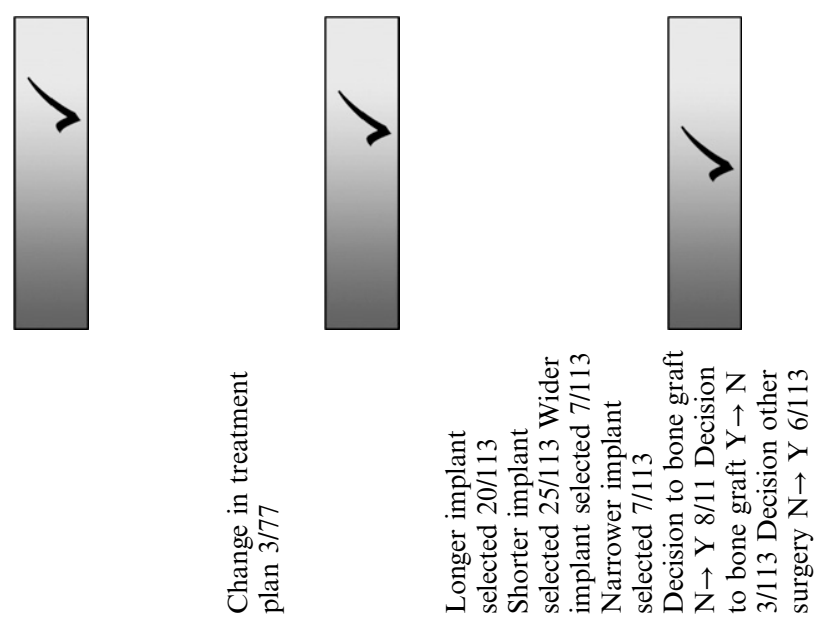

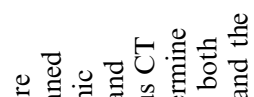

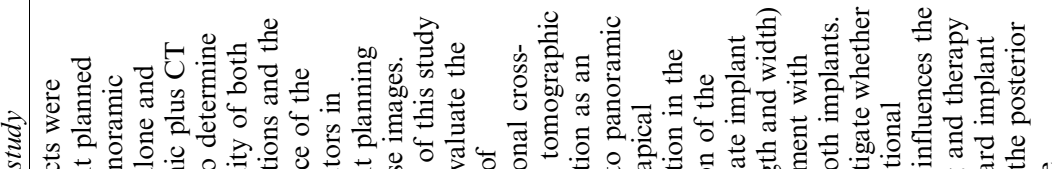

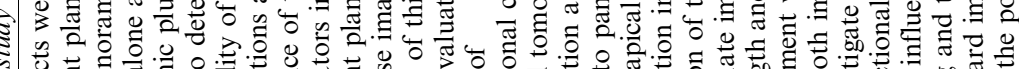

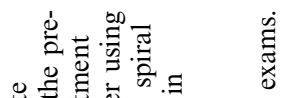

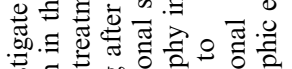

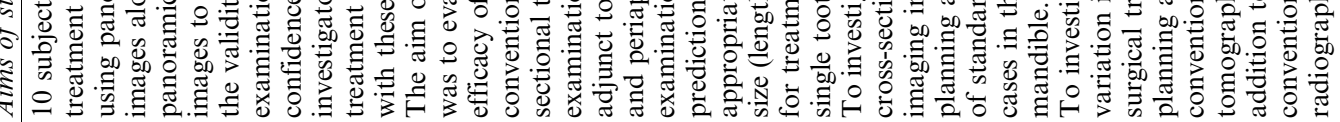

₹|
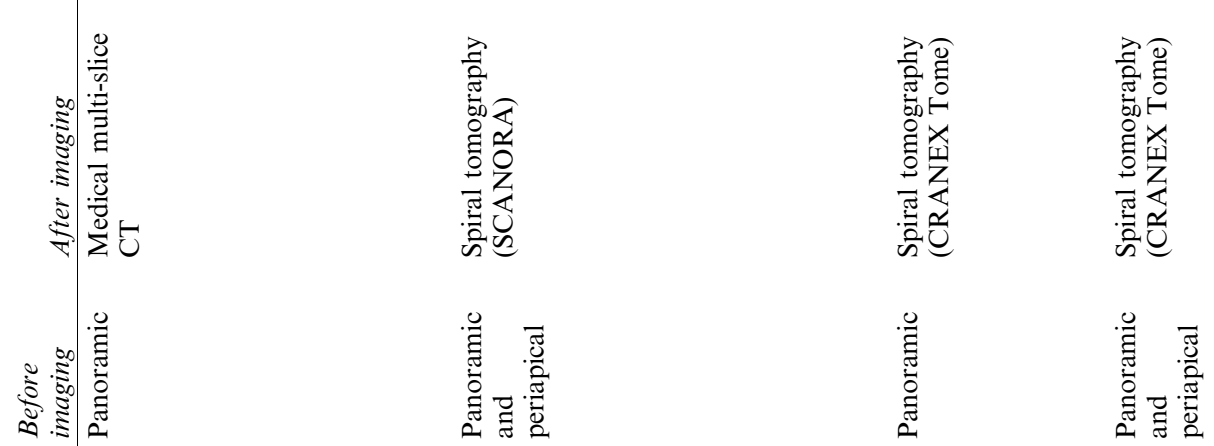

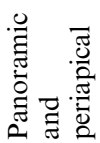

节
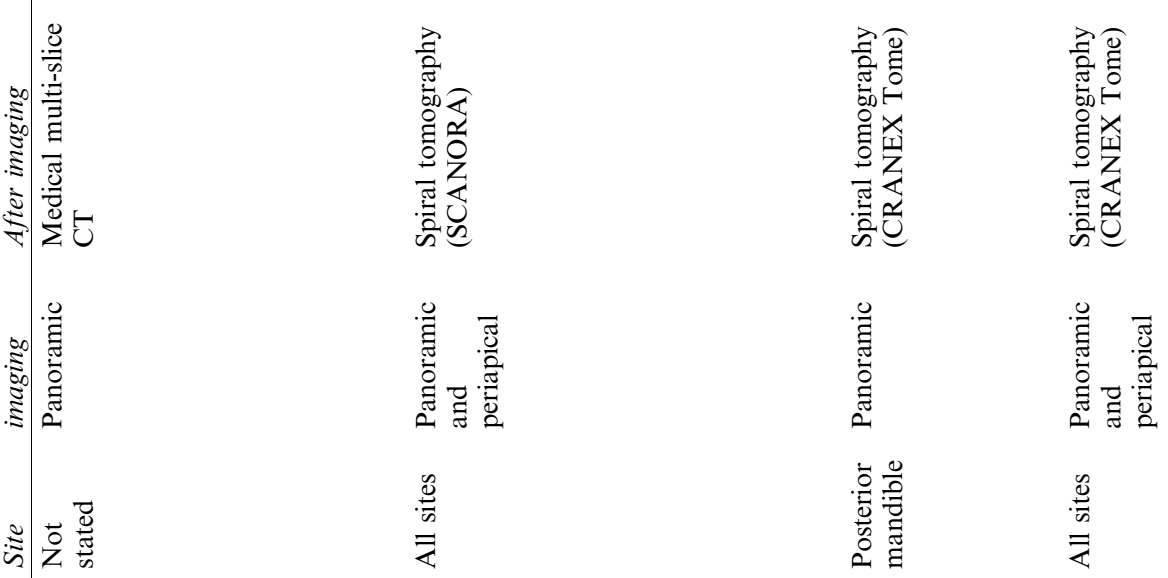

$\frac{\substack{5 \\ \frac{5}{2}}}{\gtrless}$

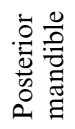

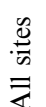

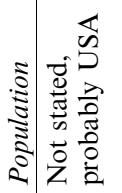

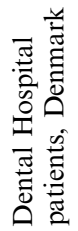

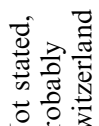

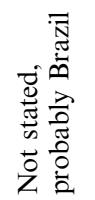

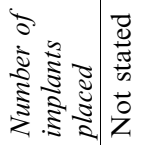

\&

단

$\stackrel{9}{=}$
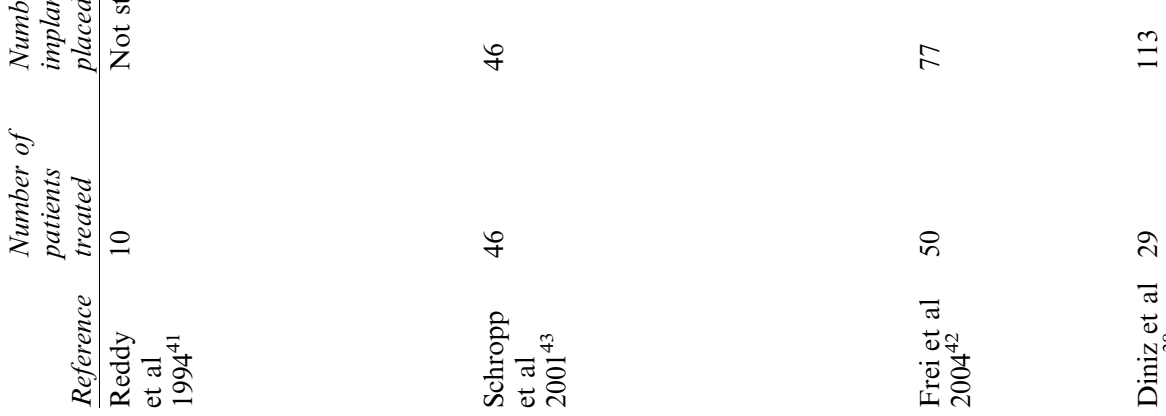


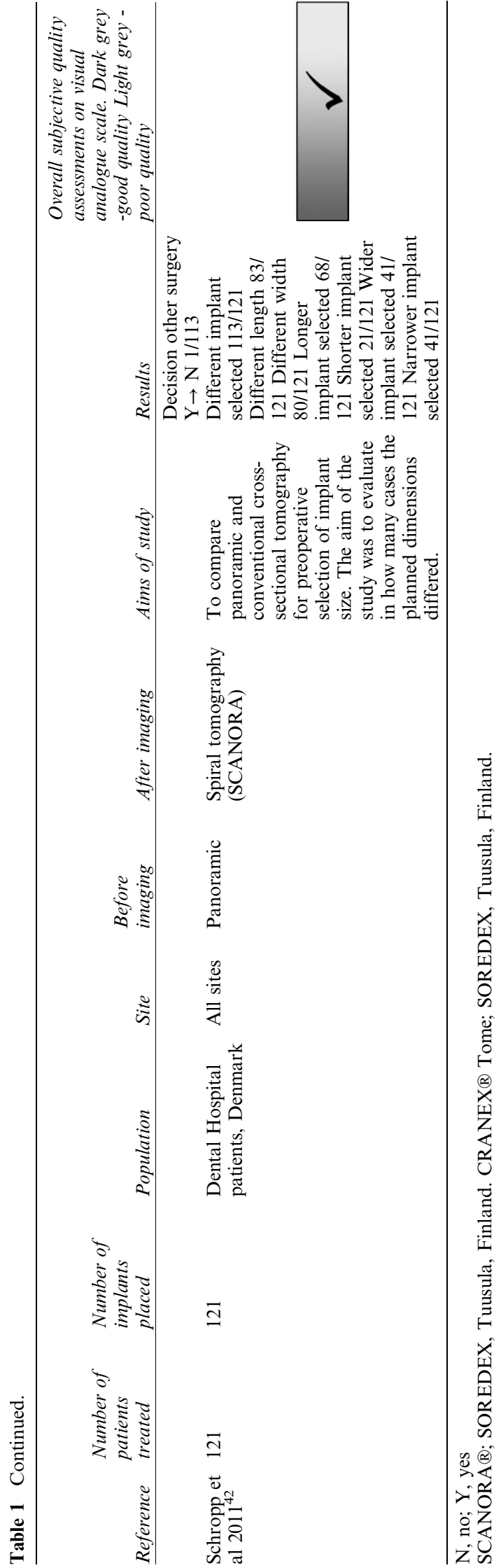

Nevertheless, the authors do report the number of patients as being 10 . Therefore, 10 implants are represented as being the minimum number placed.

No single consistent outcome measure was found. In four of the studies, implant length was considered. ${ }^{38,41-43}$ Of these four studies, three also considered implant width. ${ }^{38,42,43}$ In another study, the outcome measure was simply "change" or "no change" in the treatment plan. ${ }^{40}$ In one of the studies, the necessity for bone grafting or sinus augmentation surgery was also recorded. ${ }^{38}$ In yet another, the authors recorded the implant selection after the availability of two-dimensional images, after the availability of three-dimensional images and then the selection of implants at the time of surgery. ${ }^{43}$

\section{Discussion}

This systematic review evaluates diagnostic and therapeutic impact rather than technical or diagnostic accuracy. The existing quality assessment tools Quality Assessment of Diagnostic Accuracy Studies and Quality Assessment of Diagnostic Accuracy Studies 2 are designed for the quality assessment of diagnostic accuracy studies and are, therefore, not appropriate for this review. The rapid scoping exercise returned only observational studies of the "beforeafter" design. In 2009, Albon et al ${ }^{64}$ carried out a similar systematic review of the impact of structural neuroimaging in psychosis. Similarly, the authors expected to identify only observational before-after studies, and they found that no validated quality assessment tool existed for systematic review of this study design. In response, two of the authors, Meads and Davenport, ${ }^{65}$ reported the development and validation of a quality assessment tool for before-after studies. This was an adaptation of the original Quality Assessment of Diagnostic Accuracy Studies tool. The quality assessment tool of Mead and Davenport was used as a starting point for the development of a quality assessment tool for this review.

No randomized controlled studies were found in the literature search. Only five studies were identified. These were of the uncontrolled before-after design. Uncontrolled observational studies, such as these, already have intrinsic bias. The Cochrane Effective Practice and Organization of Care group comment, "It is difficult, if not impossible, to attribute causation from such studies" ${ }^{66}$ Reeves et al ${ }^{67}$ further state "Potential biases are likely to be greater for non-randomised studies compared with randomised trials, so results should always be interpreted with caution when they are included in reviews and meta-analyses". Nevertheless, this should not imply that non-randomized studies are not of value. A systematic review of the results of randomized and non-randomized prospective studies, evaluating 45 medical interventions, showed that evidence from nonrandomized studies is important. ${ }^{68}$ The authors found good correlation between the results of randomized and prospective non-randomized studies, as long as the quality of non-randomized studies was high. 


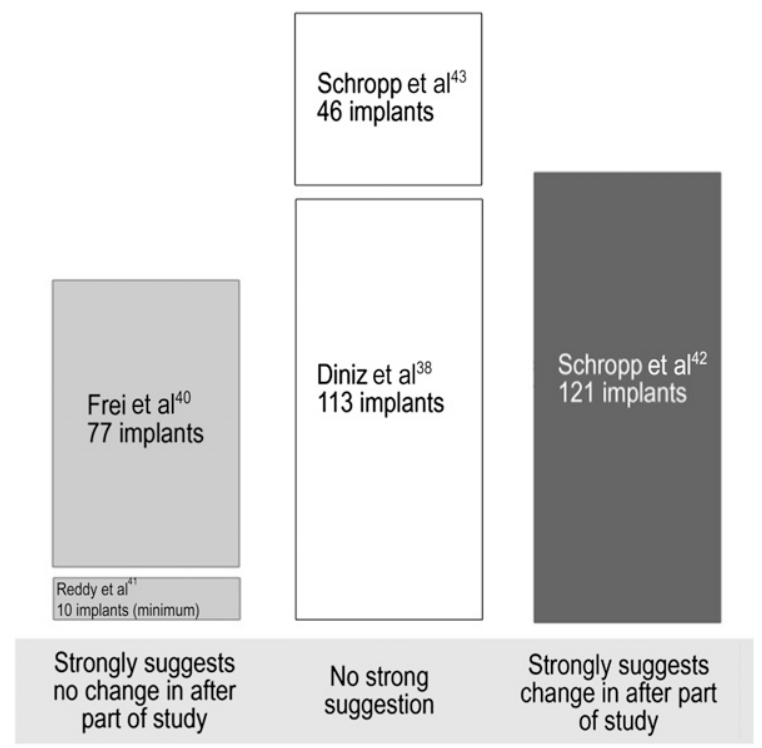

Figure 3 Synthesis according to number of implants placed in the studies. Column heights are proportional to number of implants in each study. Studies are arranged in columns according to the impact on the treatment plan.

It would have been reasonable to have excluded the study by Reddy et $\mathrm{al}^{41}$ from this review on the basis that the number of patients was specified but not the number of implants which were placed. Certainly, this study would have been excluded from a quantitative analysis had this been possible. Nevertheless, in view of the small number of identified studies, it was agreed to include this investigation in a narrative synthesis. Furthermore, although this was the oldest study, it was the only one that investigated the impact of CT. All other studies investigated conventional spiral tomography.

In these studies, the largest number of evaluators was four, ${ }^{41}$ and two of the studies had only one evaluator. ${ }^{40,43}$ Therefore, the risk of bias arising from the possible idiosyncratic practices of individual operators is inescapable. A subjective judgment, agreed amongst the reviewers, was that only one study suggested that there was a change in the "after" part of the studies. ${ }^{42}$ The other four studies suggested that there was no change or that there was no strong suggestion. Nevertheless, an interpretation of these studies might be that pre-operative cross-sectional imaging has an impact where cases are more challenging. For example, in the study by Frei et al ${ }^{40}$ narrow ridges were excluded from the study and very little difference was observed after cross-sectional imaging was introduced (4\%). Conversely, in the study of Schropp et al in $2011,{ }^{42}$ there were no exclusions, and patients were those who had been referred to a university dental hospital. It is reasonable to assume that these were more challenging cases. In this study, treatment plan changes were made in $93 \%$ of sites. Furthermore, in the study of Diniz et al, ${ }^{38}$ statistically significant changes were observed in those more difficult cases, which were considered for bone grafting or

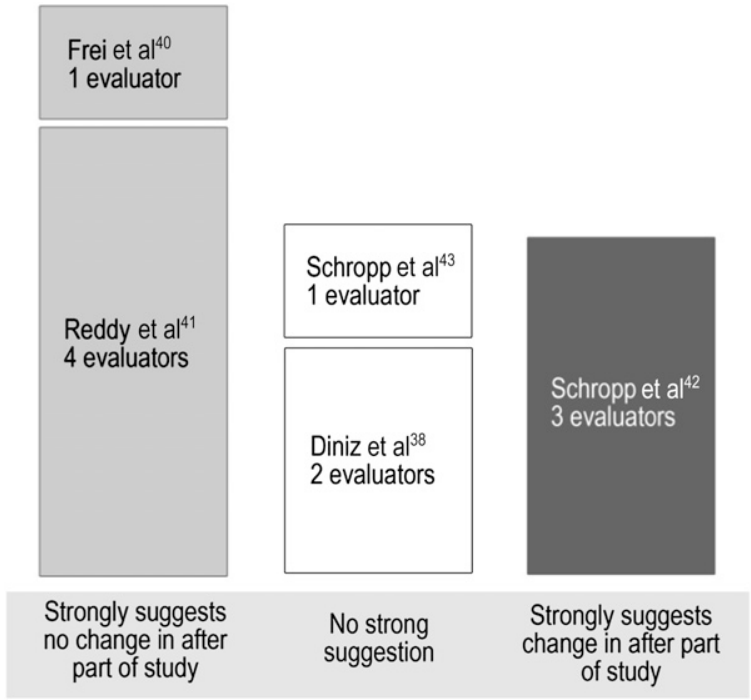

Figure 4 Synthesis according to number of evaluators in the studies. Column heights are proportional to number of evaluators in each study. Studies are arranged in columns according to the impact on the treatment plan.

other surgical procedures. Nonetheless, this is a very speculative conclusion given the limitations of these studies.

Only one article allowed separation of the data for dental implant placement in the anterior mandible. ${ }^{42}$ No other authors were explicit about the number of implants placed in the anterior mandible, and it is possible that no other implants were placed in this region in any of the other studies. Accordingly, the findings of this review should be interpreted with caution when applied specifically to the anterior mandible or to any area of the mouth. It must be acknowledged that, whilst all of the identified studies assessed the impact of imaging on selection of implant size, none evaluated the impact on implant position. If drilling perforates the lingual cortical plate of bone then the network of vessels arising from the sublingual and submaxillary arteries may be traumatized causing a potentially fatal haematoma. It is clearly possible that osteotomy preparation for the same size of implant may be placed safely within bone or that it may perforate the lingual cortical plate. There is a need for practical studies, which evaluate the impact of different imaging modalities when drilling osteotomies for dental implant placement.

In conclusion, little can be determined from a synthesis of these studies because of their small number, clinical diversity and high risks of bias. Notwithstanding, it may be tentatively inferred that cross-sectional imaging has an impact on the more challenging cases. No studies were returned from the search that assessed the impact of cone beam CT technology. This became widely available around 2005 and might now be regarded as having superseded conventional tomography and, for head and neck imaging, multislice medical CT. In that regard, these studies are only partly helpful 

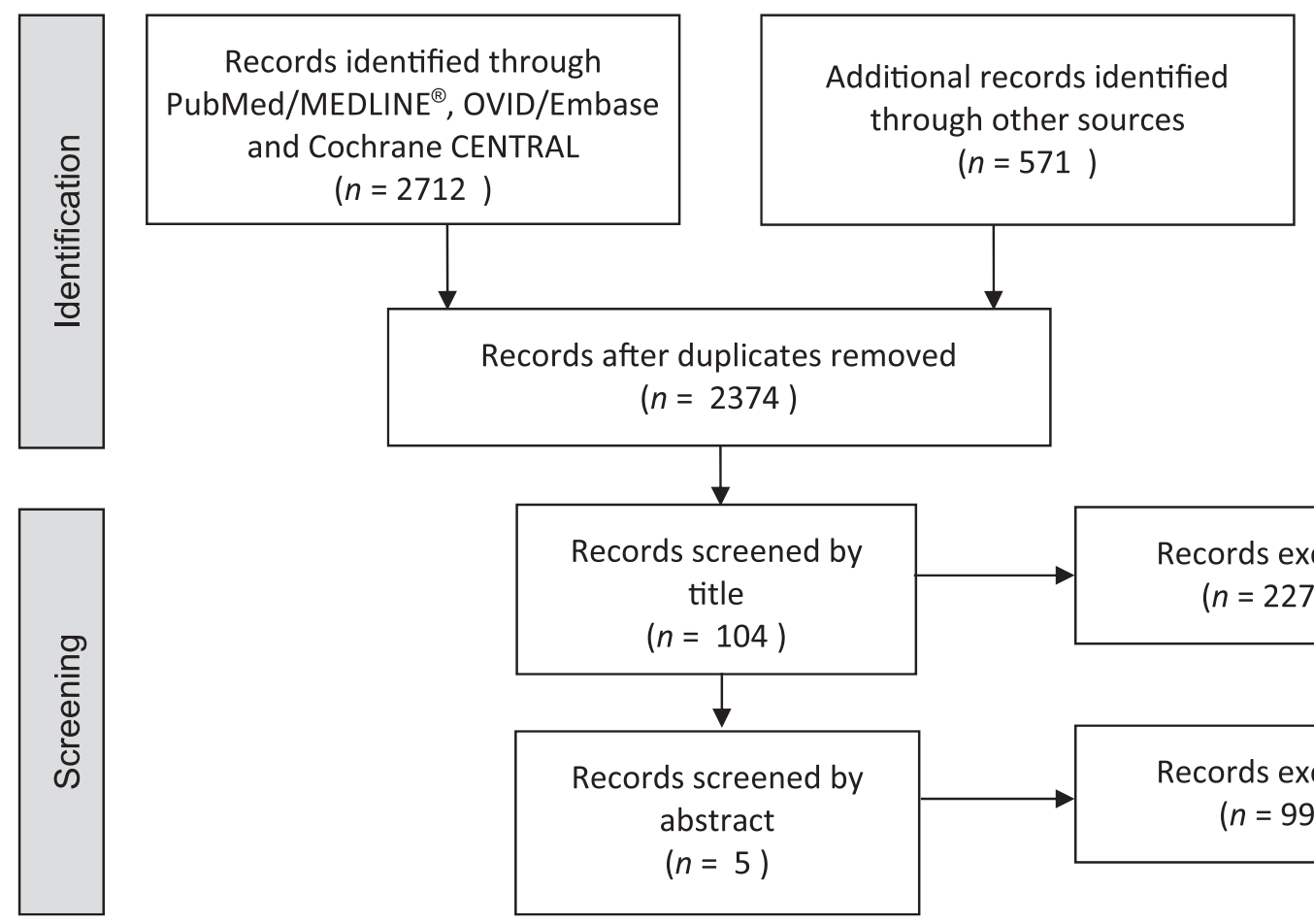

$(n=2374)$
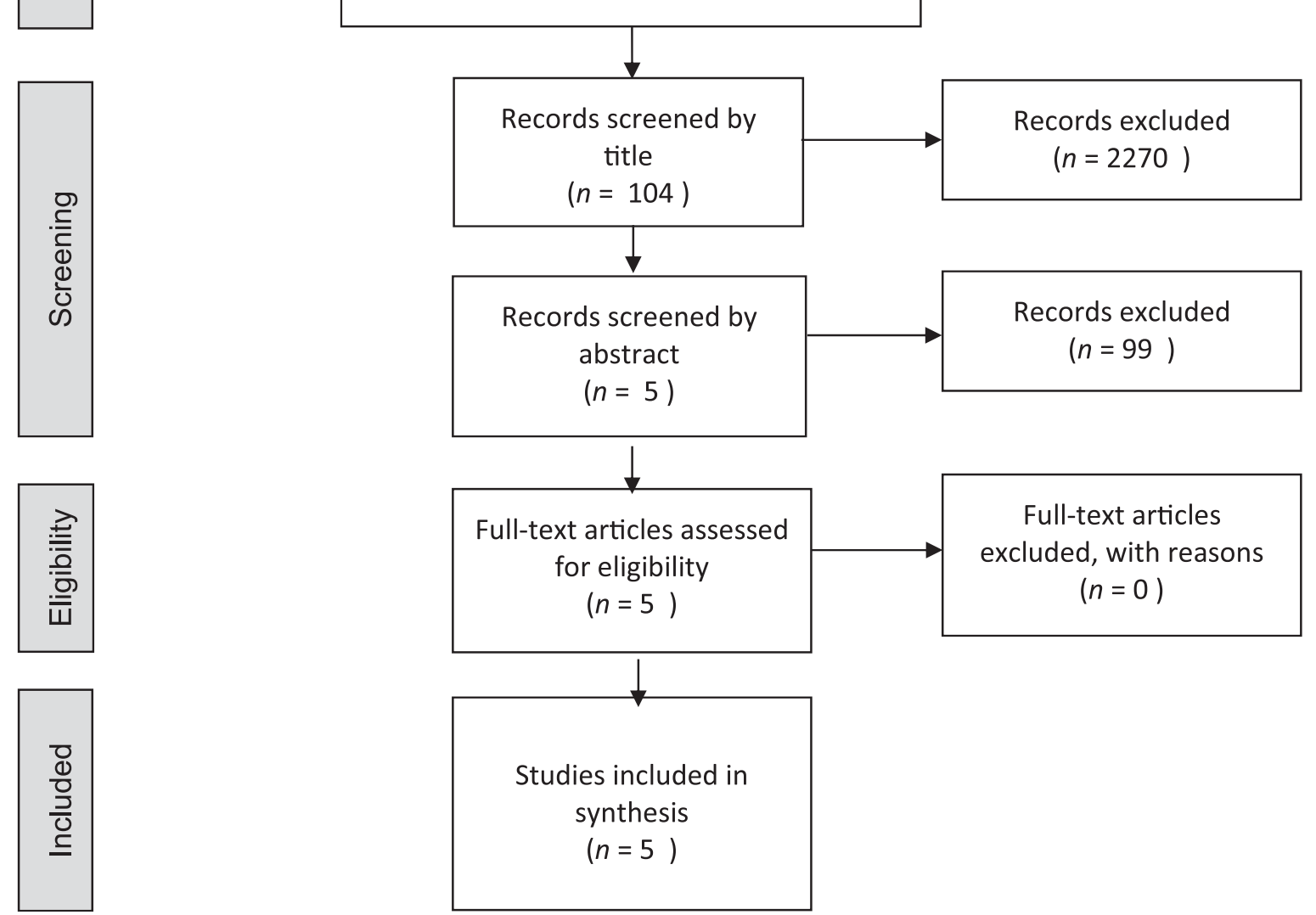

Figure 5 Preferred Reporting Items for Systematic Reviews and Meta-Analyses diagram of results of searches and study selection.

regarding currently used technology. The higher levels of evaluation of the efficacy of diagnostic imaging are Levels 3-6. These were described by Fryback and Thornbury $^{31}$ and concern the impact of diagnostic imaging. In terms of efficacy at these higher levels of evaluation, this review has found no evidence to support any specific imaging modality when planning dental implant placement in any region of the mouth. Therefore, those who argue that cross-sectional imaging should be used for the assessment of all dental implant sites are unsupported by evidence. ${ }^{26}$ This is, of course, also true for those who argue that conventional radiography is preferred.

\section{Acknowledgments}

The authors wish to thank Dr Catherine Meads, Reader in Health Technology Assessment of Brunel University London, for her valuable advice on development of the quality assessment tool. The authors wish to thank Anne Littlewood, Trials Search Co-ordinator of the Cochrane Oral Health Group, for her kind assistance in development of the search strategy. 


\section{References}

1. Thomason JM, Feine J, Exley C, Moynihan P, Muller F, Naert I, et al. Mandibular two implant-supported overdentures as the first choice standard of care for edentulous patients-the York Consensus Statement. Br Dent $J$ 2009; 207: 185-6. doi: 10.1038/sj. bdj.2009.728

2. Chee W, Jivraj S. Treatment planning of the edentulous mandible. Br Dent J 2006; 201: 337-47. doi: 10.1038/sj.bdj.4814041

3. Feine JS, Carlsson GE, Awad MA, Chehade A, Duncan WJ, Gizani S, et al. The McGill consensus statement on overdentures. Mandibular two-implant overdentures as first choice standard of care for edentulous patients. Gerodontology 2002; 19: 3-4.

4. Lekholm U, Zarb GA. Patient selection and preparation. Chicago, IL: Quintessence; 1985.

5. Kalpidis CD, Setayesh RM. Hemorrhaging associated with endosseous implant placement in the anterior mandible: a review of the literature. J Periodontol 2004; 75: 631-45. doi: 10.1902/ jop.2004.75.5.631

6. Boyes-Varley JG, Lownie JF. Haematoma of the floor of the mouth following implant placement. SADJ 2002; 57: 64-5.

7. Darriba MA, Mendonca-Caridad JJ. Profuse bleeding and lifethreatening airway obstruction after placement of mandibular dental implants. J Oral Maxillofac Surg 1997; 55: 1328-30.

8. Del Castillo-Pardo de Vera JL, Lopez-Arcas Calleja JM, Burgueno-Garcia M. Hematoma of the floor of the mouth and airway obstruction during mandibular dental implant placement: a case report. Oral Maxillofac Surg 2008; 12: 223-6. doi: 10.1007/ s10006-008-0134-4

9. Flanagan D. Important arterial supply of the mandible, control of an arterial hemorrhage, and report of a hemorrhagic incident. $J$ Oral Implantol 2003; 29: 165-73. doi: 10.1563/1548-1336(2003) $029<0165$ :IASOTM $>2.3 . \mathrm{CO} ; 2$

10. Givol N, Chaushu G, Halamish-Shani T, Taicher S. Emergency tracheostomy following life-threatening hemorrhage in the floor of the mouth during immediate implant placement in the mandibular canine region. J Periodontol 2000; 71: 1893-5.

11. Isaacson TJ. Sublingual hematoma formation during immediate placement of mandibular endosseous implants. J Am Dent Assoc 2004; 135: 168-72.

12. Kalpidis CD, Konstantinidis AB. Critical hemorrhage in the floor of the mouth during implant placement in the first mandibular premolar position: a case report. Implant Dent 2005; 14: 117-24.

13. Krenkel C, Holzner K. Lingual bone perforation as causal factor in a threatening hemorrhage of the mouth floor due to a single tooth implant in the canine region. [In German.] Quintessenz 1986; 37: 1003-8.

14. Laboda G. Life-threatening hemorrhage after placement of an endosseous implant: report of case. J Am Dent Assoc 1990; 121: 599-600.

15. Mason ME, Triplett RG, Alfonso WF. Life-threatening hemorrhage from placement of a dental implant. J Oral Maxillofac Surg 1990; 48: 201-4.

16. Mordenfeld A, Andersson L, Bergstrom B. Hemorrhage in the floor of the mouth during implant placement in the edentulous mandible: a case report. Int J Oral Maxillofac Implants 1997; 12: $558-61$.

17. Niamtu J, 3rd. Near-fatal airway obstruction after routine implant placement. Oral Surg Oral Med Oral Pathol Oral Radiol Endod 2001; 92: 597-600. doi: 10.1067/moe.2001.116503

18. Panula K, Oikarinen K. Severe hemorrhage after implant surgery. Oral Surg Oral Med Oral Pathol Oral Radiol Endod 1999; 87: 2.

19. Pigadas N, Simoes P, Tuffin JR. Massive sublingual haematoma following osseo-integrated implant placement in the anterior mandible. Br Dent J 2009; 206: 67-8. doi: 10.1038/sj.bdj.2009.2

20. Ratschew C, Czernicky W, Watzek G. Lebensbedrochliche Blutung nach Implantation im Unterkiefer. Dtsch Zahnarztl Z 1994; 49: 65-7.

21. ten Bruggenkate CM, Krekeler G, Kraaijenhagen HA, Foitzik C, Oosterbeek HS. Hemorrhage of the floor of the mouth resulting from lingual perforation during implant placement: a clinical report. Int J Oral Maxillofac Implants 1993; 8: 329-34.

22. Weibrich G, Foitzik Ch, Kuffner H. Life threatening oral hemorrhage after implantation into the distal right mandible. [In German.] Mund Kiefer Gesichtschir 2002; 6: 442-5. doi: 10.1007/ s10006-002-0411-6

23. Woo BM, Al-Bustani S, Ueeck BA. Floor of mouth haemorrhage and life-threatening airway obstruction during immediate implant placement in the anterior mandible. Int J Oral Maxillofac Surg 2006; 35: 961-4. doi: 10.1016/j.ijom.2006.03.020

24. Hofschneider U, Tepper G, Gahleitner A, Ulm C. Assessment of the blood supply to the mental region for reduction of bleeding complications during implant surgery in the interforaminal region. Int J Oral Maxillofac Implants 1999; 14: 379-83.

25. Longoni S, Sartori M, Braun M, Bravetti P, Lapi A, Baldoni M, et al. Lingual vascular canals of the mandible: the risk of bleeding complications during implant procedures. Implant Dent 2007; 16: 131-8. doi: 10.1097/ID.0b013e31805009d5

26. Tyndall DA, Price JB, Tetradis S, Ganz SD, Hildebolt C, Scarfe WC. Position statement of the American Academy of Oral and Maxillofacial Radiology on selection criteria for the use of radiology in dental implantology with emphasis on cone beam computed tomography. Oral Surg Oral Med Oral Pathol Oral Radiol 2012; 113: 817-26. doi: 10.1016/j.oooo.2012.03.005

27. Shelley A, Horner K. A transymphyseal X-ray projection to assess the anterior edentulous mandible prior to implant placement. Dent Update 2008; 35: 689-94.

28. Mackenzie R, Dixon AK. Measuring the effects of imaging: an evaluative framework. Clinical Radiol 1995; 50: 513-18.

29. Ramlaul A, Hogg P. Medical imaging and radiotherapy research: skills and strategies. Edinburgh, UK: Churchill Livingstone; 2010.

30. Fineberg HV. Evaluation of computed tomography: achievement and challenge. AJR Am J Roentgenol 1978; 131: 1-4. doi: 10.2214/ ajr.131.1.1

31. Fryback DG, Thornbury JR. The efficacy of diagnostic imaging. Med Decis Making 1991; 11: 88-94.

32. Brown AA, Scarfe WC, Scheetz JP, Silveira AM, Farman AG. Linear accuracy of cone beam CT derived 3D images. Angle Orthod 2009; 79: 150-7. doi: 10.2319/122407-599.1

33. Guerrero ME, Shahbazian M, Elsiena Bekkering G, Nackaerts O, Jacobs R, Horner K. The diagnostic efficacy of cone beam CT for impacted teeth and associated features: a systematic review. J Oral Rehabil 2011; 38: 208-16. doi: 10.1111/j.1365-2842.2010.02141.x

34. Haiter-Neto F, Wenzel A, Gotfredsen E. Diagnostic accuracy of cone beam computed tomography scans compared with intraoral image modalities for detection of caries lesions. Dentomaxillofac Radiol 2008; 37: 18-22.

35. Pinsky HM, Dyda S, Pinsky RW, Misch KA, Sarment DP. Accuracy of three-dimensional measurements using cone-beam CT. Dentomaxillofac Radiol 2006; 35: 410-16. doi: 10.1259/dmfr/ 20987648

36. Ribeiro-Rotta RF, Lindh C, Rohlin M. Efficacy of clinical methods to assess jawbone tissue prior to and during endosseous dental implant placement: a systematic literature review. The Int $J$ Oral Maxillofac Implants 2007; 22: 289-300.

37. Al-Ekrish AA, Ekram M. A comparative study of the accuracy and reliability of multidetector computed tomography and cone beam computed tomography in the assessment of dental implant site dimensions. Dentomaxillofac Radiol 2011; 40: 67-75. doi: $10.1259 / \mathrm{dmfr} / 27546065$

38. Diniz AF, Mendonca EF, Leles CR, Guilherme AS, Cavalcante MP, Silva MA. Changes in the pre-surgical treatment planning using conventional spiral tomography. Clin Oral Implants Res 2008; 19: 249-53. doi: 10.1111/j.1600-0501.2007.01475.x

39. Fortin T, Camby E, Alik M, Isidori M, Bouchet H. Panoramic images versus three-dimensional planning software for oral implant planning in atrophied posterior maxillary: a clinical radiological study. Clin Implant Dent Relat Res 2013; 15: 198-204. 
40. Frei C, Buser D, Dula K. Study on the necessity for cross-section imaging of the posterior mandible for treatment planning of standard cases in implant dentistry. Clin Oral Implants Res 2004; 15: 490-7.

41. Reddy MS, Mayfield-Donahoo T, Vanderven FJ, Jeffcoat MK. A comparison of the diagnostic advantages of panoramic radiography and computed tomography scanning for placement of root form dental implants. Clin Oral Implants Res 1994; 5: 229-38.

42. Schropp L, Stavropoulos A, Gotfredsen E, Wenzel A. Comparison of panoramic and conventional cross-sectional tomography for preoperative selection of implant size. Clin Oral Implants Res 2011; 22: 424-9. doi: 10.1111/j.1600-0501.2010.02006.x

43. Schropp L, Wenzel A, Kostopoulos L. Impact of conventional tomography on prediction of the appropriate implant size. Oral Surg Oral Med Oral Pathol Oral Radiol Endod 2001; 92: 458-63. doi: $10.1067 /$ moe. 2001.118286

44. Chen LC, Lundgren T, Hallstrom H, Cherel F. Comparison of different methods of assessing alveolar ridge dimensions prior to dental implant placement. J Periodontol 2008; 79: 401-5. doi: 10.1902/jop.2008.070021

45. Dreiseidler T, Mischkowski RA, Neugebauer J, Ritter L, Zoller JE. Comparison of cone-beam imaging with orthopantomography and computerized tomography for assessment in presurgical implant dentistry. Int J Oral Maxillofac Implants 2009; 24: 216-25.

46. Jacobs R, Adriansens A, Naert I, Quirynen M, Hermans R, Van Steenberghe D. Predictability of reformatted computed tomography for pre-operative planning of endosseous implants. Dentomaxillofac Radiol 1999; 28: 37-41. doi: 10.1038/sj.dmfr.4600403

47. Jacobs R, Adriansens A, Verstreken K, Suetens P, van Steenberghe D. Predictability of a three-dimensional planning system for oral implant surgery. Dentomaxillofac Radiol 1999; 28: 105-11. doi: $10.1038 / \mathrm{sj} / \mathrm{dmfr} / 4600419$

48. Schropp L, Stavropoulos A, Gotfredsen E, Wenzel A. Calibration of radiographs by a reference metal ball affects preoperative selection of implant size. Clin Oral Investig 2009; 13: 375-81. doi: $10.1007 / \mathrm{s} 00784-009-0257-5$

49. Vazquez L, Saulacic N, Belser U, Bernard JP. Efficacy of panoramic radiographs in the preoperative planning of posterior mandibular implants: a prospective clinical study of 1527 consecutively treated patients. Clin Oral Implants Res 2008; 19: 81-5.

50. Webber RL, Messura JK. An in vivo comparison of diagnostic information obtained from tuned-aperture computed tomography and conventional dental radiographic imaging modalities. Oral Surg Oral Med Oral Pathol Oral Radiol Endod 1999; 88: 239-47.

51. American Dental Association. The selection of patients for dental radiographic examinations. Chicago, IL: American Dental Association, 2004

52. Benavides E, Rios HF, Ganz SD, An CH, Resnik R, Reardon GT, et al. Use of cone beam computed tomography in implant dentistry: the International Congress of Oral Implantologists consensus report. Implant Dent 2012; 21: 78-86. doi: 10.1097/ ID.0b013e31824885b5

53. FGDP(UK). Selection criteria in dental radiography. 2nd edn. London: Faculty of General Dental Practitioners (UK) Royal College of Surgeons of England; 2004.

54. Harris D, Buser D, Dula K, Grondahl K, Harris D, Jacobs R, et al. E.A.O. guidelines for the use of diagnostic imaging in implant dentistry. A consensus workshop organized by the European
Association for Osseointegration in Trinity College Dublin. Clin Oral Implants Res 2002; 13: 566-70.

55. Harris D, Horner K, Gröndahl K, Jacobs R, Helmrot E, Benic GI, et al. E.A.O. guidelines for the use of diagnostic imaging in implant dentistry 2011. A concensus workshop organized by the European Association for Osseointegration at the Medical University of Warsaw. Clin Oral Implants Res 2012; 23: 1243-53. doi: 10.1111/j.1600-0501.2012.02441.x

56. Health Protection Agency. Guidance on the safe use of dental cone beam CT equipment. Chilton, UK: Health Protection Agency; 2010.

57. European Commission. Radiation protection 136. European guidelines on radiation protection in dental radiology. Luxembourg: Office for Official Publications of the European Communities; 2004

58. European Commission. Radiation protection 172. Evidence based guidelines on cone beam CT for dental and maxillofacial radiology. Luxembourg: Office for Official Publications of the European Communities; 2012.

59. Horner K, Islam M, Flygare L, Tsiklakis K, Whaites E. Basic principles for use of dental cone beam computed tomography: consensus guidelines of the European Academy of Dental and Maxillofacial Radiology. Dentomaxillofac Radiol 2009; 38: 187-95.

60. National Radiological Protection Board. Guidance notes for dental practitioners on the safe use of X-ray equipment. Chilton, UK: National Radiological Protection Board; 2001.

61. Tyndall DA, Brooks SL. Selection criteria for dental implant site imaging: a position paper of the American Academy of Oral and Maxillofacial radiology. Oral Surg Oral Med Oral Pathol Oral Radiol Endod 2000; 89: 630-7.

62. Berlin JA. Does blinding of readers affect the results of metaanalyses? University of Pennsylvania Meta-analysis Blinding Study Group. Lancet 1997; 350: 185-6.

63. Haines T, Kennedy C, Gross A, Goldsmith C, Hondras M, Roving I. Influence of "blinding" on selection of articles for relevance. In: 7th Cochrane Colloquium; Rome, Italy, 1999.

64. Albon E, Tsourapas A, Frew E, Davenport C, Oyebode F, Bayliss $\mathrm{S}$, et al. Structural neuroimaging in psychosis: a systematic review and economic evaluation. Health Technology Assessment 2008; 12: iii-iv, ix-163.

65. Meads CA, Davenport CF. Quality assessment of diagnostic before-after studies: development of methodology in the context of a systematic review. BMC Med Res Method 2009; 9: 3. doi: $10.1186 / 1471-2288-9-3$

66. Effective Practice and Organisation of Care (EPOC). What study designs should be included in an EPOC review and what should they be called? In: EPOC Resources for review authors. Oslo: Norwegian Knowledge Centre for the Health Services; 2013. Available at: http://epocoslo.cochrane.org/epoc-specific-resourcesreview-authors

67. Reeves BC, Deeks JJ, Higgins JPT, Wells GA. Chapter 13: including non-randomised studies. In: Cochrane handbook for systematic reviews of interventions. Chichester, UK: WileyBlackwell; 2008

68. Ioannidis JP, Haidich AB, Pappa M, Pantazis N, Kokori SI, Tektonidou MG, et al. Comparison of evidence of treatment effects in randomized and nonrandomized studies. JAMA 2001; 286: $821-30$. 